\title{
Traumatic arteriovenous fistula of the superficial temporal artery
}

\section{Fístula arteriovenosa traumática de artéria temporal superficial}

Otacílio de Camargo Júnior,2, Márcia Fayad Marcondes de Abreu², Guilherme Camargo Gonçalves de Abreu², Sthefano Atique Gabriel², Isabella Maria Machado da Silva'

\begin{abstract}
Arteriovenous fistulae of the superficial temporal artery are rare, and their principal cause is traumas. Complications include pulsatile mass, headache, hemorrhage and deformities that compromise esthetics. Treatment can be performed using conventional surgery or endovascular methods. The authors describe a case of a 44-year-old male patient who developed a large pulsating mass, extending from the preauricular region to the right parietotemporal and frontal regions after a motorcycle accident. The treatment chosen was complete surgical removal of the pulsatile mass and ligature of the vessels feeding the fistula.
\end{abstract}

Keywords: arteriovenous fistulae; superficial temporal artery; trauma.

\section{Resumo}

As fístulas arteriovenosas de artéria temporal superficial são raras, sendo o trauma sua etiologia principal. Suas complicações incluem massa pulsátil, cefaleia, hemorragia e deformidade estética. O tratamento pode ser realizado por cirurgia convencional ou endovascular. Os autores relatam o caso de um paciente de 44 anos que evoluiu com massa pulsátil extensa desde região pré-auricular até região parietotemporal e frontal direita após acidente motociclístico. Optou-se por remoção cirúrgica completa da massa pulsátil e ligadura dos vasos nutridores da fístula.

Palavras-chave: fístula arteriovenosa; artéria temporal superficial; trauma. 


\section{INTRODUCTION}

Arteriovenous fistula of the superficial temporal artery is a rare condition, with an estimated incidence of $0.5 \%$ to $2.0 \%$ of cases. ${ }^{1,2}$ In $75 \%$ of patients, etiology is traumatic and these fistulae can be caused by blunt or penetrating traumas or by iatrogenic injuries during diagnostic and therapeutic procedures. ${ }^{1,2}$

Arteriovenous fistulae are connections between an arterial segment and the venous drainage system, resulting in a tortuous dilated vein and emergence of aneurysmal varicose segments, which can progress to thrombosis, ulceration and rupture. ${ }^{1,2}$

The objective of this study is to describe a case of traumatic arteriovenous fistula of the temporal superficial artery ha was treated surgically.

\section{CASE DESCRIPTION}

An otherwise healthy, 44-year-old male patient with no history of comorbidities was referred to the clinic complaining of a painless pulsating mass that was growing progressively, in a right frontal and preauricular position, and was causing a pulsing buzz in the right ear.

The patient had suffered a motorbike accident 10 years previously that had caused a stellate laceration injury to the right preauricular region. He reported that he had received care at a hospital where laboratory tests and cranial tomography had found no further abnormalities and the stellate laceration wound had been treated by debridement of devitalized tissues and closure with sutures. One year after the accident, the patient had noticed a murmur in the region of the right ear and a swelling in the right parietal region and had sought medical attention, but had not been treated. Fifteen months later he had noted a progressive increase in the murmur and in the volume of the pulsating mass in the frontal, parietal preauricular areas, causing strong headaches, significant cranial discomfort and unsightly esthetics in addition to preventing the right eye from opening normally.

On physical examination an extensive, painless and immobile pulsating mass was observed to extend from the right preauricular region to the right parietotemporal and frontal region (Figure 1). A thrill was detected on palpation of the mass and auscultation revealed a continuous murmur, with accentuated systolic sounds. Both thrill and murmur ceased when the right superficial temporal artery was compressed. After detailed physical examination a small scar was found in the right preauricular region, in the probable location from which the pulsating mass originated. A careful neurological examination detected no abnormalities.

The patient underwent cranial tomography, which found no intracranial involvement. Selective arteriography of the right external carotid artery showed premature opacification of the right superficial temporal vein, which was dilated and tortuous, and a high flow rate arteriovenous fistula (Figure 2). The fistula was fed by the superficial temporal artery and drained via the superficial temporal vein into the external jugular vein. There was no collateral circulation from the left external

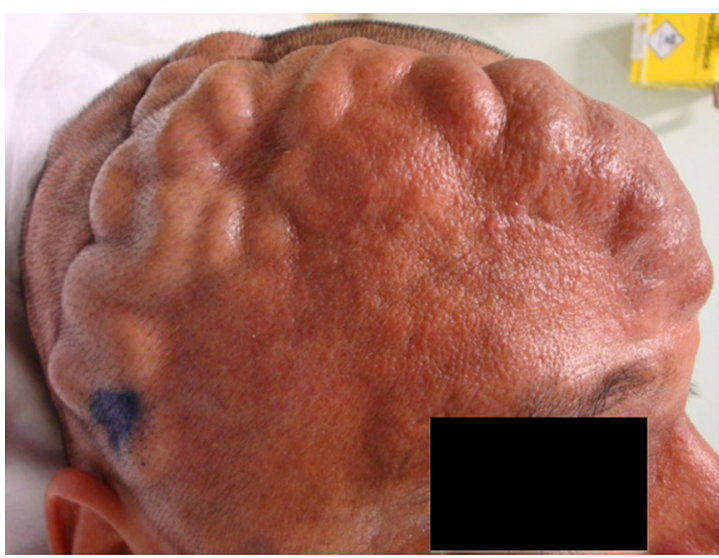

Figure 1. Arteriovenous Fistula of the Superficial Tempora Artery.

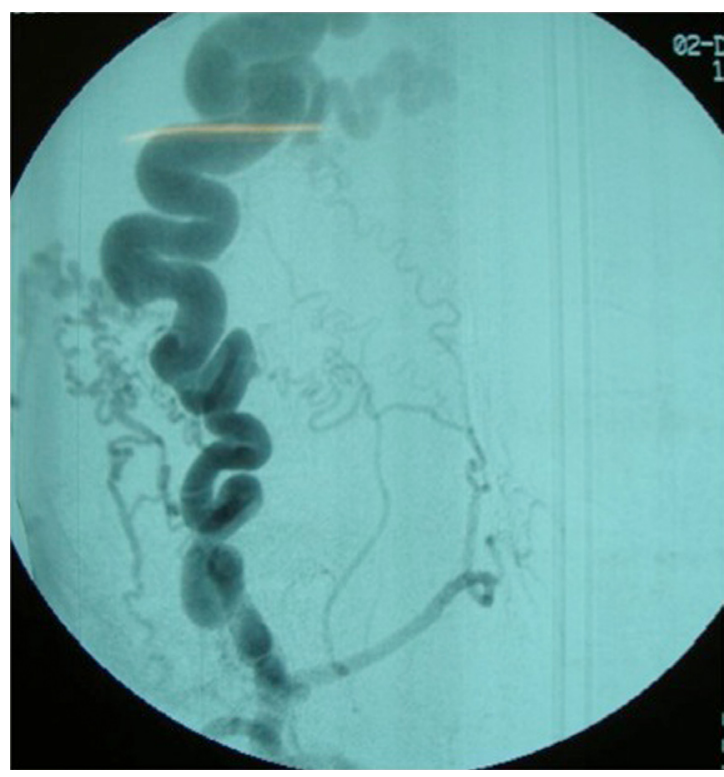

Figure 2. Selective arteriography of the right external carotid artery, showing premature opacification of the right superficial temporal vein, which is dilated and tortuous. 
carotid artery to the fistula. No communication was observed between circulation in the internal carotid artery and the arteriovenous fistula of the external carotid artery.

The decision was taken to employ conventional treatment. The patient was positioned with the head elevated by 20-30 degrees above the level of the heart to improve venous drainage. After general anesthetic, transverse incisions were made in the scalp and the arteriovenous malformations were carefully dissected, then ligated, sectioned and resected (Figure 3). The patient progressed satisfactorily, free from infection or necrosis of the scalp and with evident improvement in esthetic appearance (Figure 4).

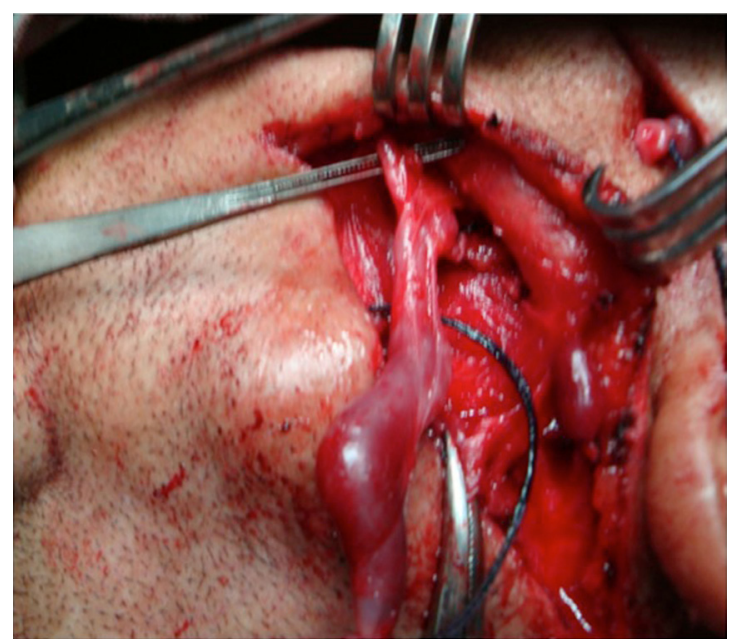

Figure 3. Intraoperative view

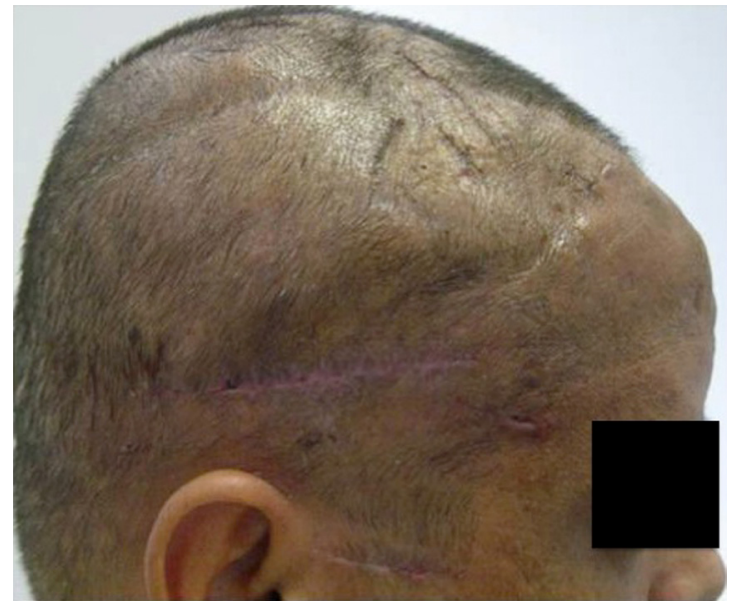

Figure 4. Postoperative view.

\section{DISCUSSION}

The superficial temporal artery is vulnerable to trauma because of its superficial path over the temporal bone and because of its proximity to cranial sutures. In addition to traumatic etiologies, arteriovenous fistulae of the superficial temporal artery can also be spontaneous or caused by surgical procedures, such as, capillary implants, external ventricular drainage and craniotomies..$^{3-5}$ Traumatic fistulae develop over the course of months or years after the trauma; while spontaneous fístulae may be present at birth, although in the majority of patients they are asymptomatic until puberty.,4 Traumas, vasomotor disorders, hormonal stimuli and inflammatory processes worsen the symptoms. ${ }^{3,4}$

Two mechanisms have been suggested to explain the formation of traumatic arteriovenous fistulae in the scalp. By the first mechanism, a simultaneous laceration of the artery and the adjacent vein leads to formation of the fistula. ${ }^{6,7}$ The second mechanism begins with rupture of vasa vasorum in the artery wall, proliferation of endothelial cells from the damaged vasa vasorum then forms numerous small vessels, creating vascular communication channels between artery and vein. ${ }^{6,7}$ In the case of the patient described here, the small scar in the right preauricular region suggests a direct connection from the artery to the superficial temporal vein caused by a traumatic laceration.

Diagnosis of a traumatic fistula of the superficial temporal artery is based on a history of trauma and a detailed physical examination..$^{6-8}$ Although angiotomography can provide images in shorter acquisition times and offers reconstruction of images in finer slices, angiography remains the gold standard examination, revealing donor and recipient vessels, excluding intracranial components and providing information about the direction and velocity of blood flow. ${ }^{6-8}$ Some traumatic lesions in superficial temporal artery topographies may not pulse or may pulse because of transmission from adjacent arteries, meaning that pseudoaneurysms, true aneurysms, arteriovenous malformations, cysts, abscesses, hematoma and aneurysms of the medial meningeal artery with bone erosion are all part of differential diagnosis of traumatic arteriovenous fistulae of the superficial temporal artery. ${ }^{6-8}$

Treatment for arteriovenous fistulae of the superficial temporal artery should take account of the elevated blood flow through the fistula, the complex vascular anatomy and the esthetic issues involved. ${ }^{9,10}$ Treatment is indicated to reduce esthetic problems, to prevent hemorrhage and ischemic skin erosion 
and other symptoms such as headaches and buzzing sounds. ${ }^{9,10}$ Treatment options include surgical excision, ligature of the vessels providing blood supply, transarterial and transvenous embolization and injection of sclerosing agents into the lesion. ${ }^{9,10}$

Endovascular embolization can be employed as a definitive treatment or as an adjuvant to a surgical procedure, reducing blood loss during removal of the pulsating mass; but it is not alone sufficient for extensive arteriovenous fistulae, providing only temporary relief from symptoms, involving a high risk of recurrence and conferring a risk of cutaneous necrosis. ${ }^{9} 10$ Surgical removal of the pulsating mass and ligature of the vessels feeding the arteriovenous fistulae remains the treatment of choice..$^{9,10}$

\section{REFERENCES}

1. Miekisiak G, Mis M, Sandler A, Druszcz A. latrogenic arteriovenous fistula of the superficial temporal artery. Oral Maxillofac Surg. 2008;12(4):219-21. http://dx.doi.org/10.1007/s10006-008-0133-5

2. Li F, Zhu S, Liu Y, et al. Traumatic arteriovenous fistula of the superficial temporal artery. J Clin Neurosci. 2007;14(6):595-600. http://dx.doi.org/10.1016/j.jocn.2006.04.011

3. Senoglu M, Yasim A, Gokce $M$, Senoglu N. Nontraumatic scalp arteriovenous fistula in an adult: technical report on an illustrative case. Surg Neurol. 2008;70(2):194-7. http://dx.doi.org/10.1016/j. surneu.2007.04.018

4. Leal FS, Miranda CC, Guimarães AC. Traumatic pseudoaneurysm of the superficial temporal artery: case report. Arq Neuropsiquiatr. 2005;63(3B):859-61. http://dx.doi.org/10.1590/ S0004-282X2005000500027

5. Bernstein J, Podnos S, Leavitt $M$. Arteriovenous fistula following hair transplantation. Dermatol Surg. 2011;37(6):873-5. http:// dx.doi.org/10.1111/j.1524-4725.2011.02027.x

6. Kelly K, Trites JR, Taylor SM, Bullock M, Hart RD. Arteriovenous malformation of the scalp with cerebral steal. Head Neck. 2009;31(11):1520-3. http://dx.doi.org/10.1002/hed.21032

7. Hasturk AE, Erten F, Ayata T. Giant non-traumatic arteriovenous malformation of the scalp. Asian J Neurosurg. 2012;7(1):39-41. http://dx.doi.org/10.4103/1793-5482.95698

8. Mishra SS, Panigrahi S, Parida D, Behera SK. Usefulness of computed tomographic angiography in the management of extracranial scalp arteriovenous malformation. Neurol India. 2012;60(3):357-8. http://dx.doi.org/10.4103/0028-3886.98544

9. Whiteside OJ, Monksfield P, Steventon NB, Byrne J, Burton MJ. Endovascular embolization of a traumatic arteriovenous fistula of the superficial temporal artery. J Laryngol Otol. 2005;119(4):322-4. http://dx.doi.org/10.1258/0022215054020368

10. Yablonicky KJ, Desai S. A case report of a scalp arteriovenous malformation after trauma. J Emerg Med. 2011;41(5):e117-9. http://dx.doi.org/10.1016/j.jemermed.2009.07.039 